\title{
Evolution of HIV/AIDS Policy
}

\author{
Fan Lu, Peng Xu, Jennifer M. McGoogan, Wanying Chen, \\ and Liping $\mathrm{Ma}$
}

\begin{abstract}
The HIV/AIDS-related policy framework in China has come a long way from initially attempting to prevent HIV from entering the country in the early stages of the epidemic to facilitating comprehensive national HIV response of today. Each step of the way, policymakers in China have strived to ensure that HIVrelated policies were pragmatic, tailored to the Chinese context, aligned with international best practices, and based upon the best available information at the time. Although there have been a great many policy actions since HIV was first discovered on the mainland, a few key policies were foundational, had a major impact on the epidemic, and marked an important shift China's HIV response, for example, the Blood Donation Law (1998), the first Five-Year Action Plan for the Containment and Control of HIV/AIDS (2001), and the "Four Frees and One Care" policy (2003). These and other key policies are highlighted here. Going forward, as China's HIV epidemic increases in size and complexity, policymakers need to remain grounded in evidence but also be open to alternative and innovative approaches.
\end{abstract}

F. Lu ( $\triangle)$ P. Xu · J. M. McGoogan · W. Chen · L. Ma

NCAIDS, China CDC, Beijing, China

e-mail: fanlv@chinaaids.cn 


\subsection{Introduction}

China has sought to develop and implement HIV/AIDS-related policies that are pragmatic, tailored to the Chinese context, aligned with international best practices, and based upon the best available information at the time. For roughly 10 years after the first HIV case was first discovered on the mainland in 1986 (a foreign national diagnosed with AIDS), the best information available was from case reporting. However, during this period, nearly all cases were identified very late, when patients presented to hospitals with already severe symptoms of advanced HIV disease or AIDS. Thus, case reporting information was already many years out of date, and policymakers were unable to see the current picture of the HIV epidemic during this time. To make matters worse, while there were certainly more people living with HIV (PLWH) who were still undiagnosed compared to those diagnosed and therefore counted among case reports (i.e. a total of 20,711 by the end of 2003), there was uncertainty and substantial worry surrounding just how many Chinese citizens had HIV infection and did not know it (Wang et al. 2010).

Thus, on advice from the World Health Organization (WHO) and under the leadership of the Chinese Academy of Preventive Medicine (the institute was renamed as Chinese Center for Disease Control and Prevention-China CDC, in 2002), the National HIV Sentinel Surveillance System was developed and launched in 1995. This system did not take the place of case reporting. Rather, it acted in parallel, and the two sources of information were complementary to each other. The surveillance system began with collection of data among key, high-risk groups including drug users, female sex workers (FSW), pregnant women, sexually transmitted infection (STI) clinic attendees, long-distance truck drivers, and military recruits. It also began with data collection in geographical areas most affected by the HIV epidemic based on case reports, for example, Yunnan province. Although the system started out very small, with only 42 sentinel sites operating from 1995 to 1996, it quickly expanded both in terms of numbers of sites (i.e. 101 by 2000 and 194 by 2003) and in terms of key populations covered (i.e. former plasma donors [FPD] were added in 1998, men who have sex with men [MSM] were added in 2002). This system became a key source of information for HIV/AIDS policy formulation (Lin et al. 2012) (see Chap. 2 for more information).

Also important in shaping HIV/AIDS-related policy in China was an international agreement made in 2004 among international aid agencies and other donors, developing countries, and United Nations (UN) agencies. The core principles of this agreement, called the "Three Ones," were:

one agreed HIV/AIDS action framework that provides the basis for coordinating the work of all partners, one national AIDS coordinating authority, with a broad based multi-sector mandate, and one agreed country-level monitoring and evaluation system.

The purpose of these principles was to help ensure that the global HIV/AIDS response was well coordinated among members of the international community and to ensure that limited resources were used as efficiently as possible with a goal of 
targeting priority issues, making maximal impact, and preventing duplication of effort (Joint United Nations Programme on HIV/AIDS 2004).

Over time, more sources of information became available that were also important in further understanding China's HIV epidemic and informing policy supporting China's HIV/AIDS response. For example, behavioral surveillance among some risk groups began in 2004, active testing campaigns were launched in 2004 and 2005, improved methods of estimating the total number of PLWH in China (diagnosed and undiagnosed) were incorporated and made routine in 2005, and several large, special epidemiological surveys were conducted beginning in the latter half of the 2000s. Many international aid programs were also generating data during this time as well and all of these sources of partially overlapping and nonstandardized data gathered via disparate methods began to be overwhelming. The days of not having enough data were over, but the true nature of the epidemic was not clearer. Thus, in 2008, China launched its National HIV/AIDS Comprehensive Response Information Management System (CRIMS), which integrated eight smaller systems (i.e. case reporting, testing and counseling, sentinel surveillance, behavioral surveillance, antiretroviral therapy [ART] for adults, ART for children, high-risk group behavioral intervention, and methadone maintenance treatment [MMT]) and one new system (i.e. county demographic information) into a single, unified, web-based, real-time monitoring and evaluation data system. From 2008 on, CRIMS has been the primary source of data informing policy development and implementation for China's HIV/ AIDS response (Mao et al. 2010) (see Chap. 24 for more information).

The Chinese Government at all levels has issued hundreds of HIV/AIDS-related policies since the start of the epidemic, and they cannot all be covered in detail here. Thus, this chapter highlights some of the most significant national-level policies, which were critically important to China's HIV/AIDS response.

\subsection{Key HIV/AIDS Policies}

An overview of the major, national-level HIV/AIDS-related policies issued by the Chinese Central Government is summarized in chronological order in Table 18.1. This overview is provided along with a short description of the status of the HIV epidemic at the time these policies were issued (see Chap. 1 for more information).

\subsubsection{Implementation and Repeal of the Travel Ban}

By 1988, 22 HIV/AIDS cases had been reported on the mainland, mostly among foreigners, Chinese residents returning from overseas, or locals who had received imported blood products that were contaminated. This spurred the Chinese Government to take action, issuing a series of early policies focused mainly on preventing the virus from entering the country, whether carried by infected individuals or by contaminated blood products. Foreign students, researchers, business people, and others visiting China on 12-month visas had to submit to an HIV test within 
1 month of entering the country. Foreigners already residing in China for more than 12 months were required to provide health certificates that specified HIV status. HIV testing was set up at major border crossings and customs checkpoints and in large cities. Foreigners attempting to enter the country who were found to have HIV infection were denied entry, quarantined, and then deported (Ministry of Health 1985; Ministry of Health et al. 1988; Ministry of Public Security and Ministry of Foreign Affairs 1986; State Education Commission and Ministry of Health of China 1986; Ministry of Health and Ministry of Public Security 1987; Sun et al. 2010).

The travel ban was temporarily lifted for a few special events including, for example, the 1990 Asian Games, the 1995 UN Fourth World Conference on Women, the 2007 Global Fund Board Member Meeting, and the 2008 Olympics Games. However, over time and with improved quality and timeliness of data, officials

Table 18.1 An overview of key, national-level HIV/AIDS policies. Adapted with permission from Sun et al. (2010)

\begin{tabular}{|c|c|}
\hline HIV epidemic status & Policy and response \\
\hline $\begin{array}{l}\text { 1985-1988: In 1985, a US } \\
\text { citizen was diagnosed with } \\
\text { HIV infection while traveling } \\
\text { in China, and four patients } \\
\text { with hemophilia, treated with } \\
\text { imported blood products, } \\
\text { were also diagnosed with } \\
\text { HIV. By 1988, a total of } 22 \\
\text { cases had been reported } \\
\text { across seven provincial-level } \\
\text { administrative areas, most } \\
\text { among foreigners or citizens } \\
\text { returning from abroad (see } \\
\text { Chap. } 1 \text { for more information) }\end{array}$ & $\begin{array}{l}\text { The Chinese Central Government responded with policies } \\
\text { aimed at stopping HIV from entering China and at initiating } \\
\text { case reporting } \\
\text { 1984: Blood Product Imports -This policy banned the } \\
\text { importation of foreign blood products into China (Ministry of } \\
\text { Health 1984) } \\
\text { 1985: Surveillance of Imported Cases-This policy } \\
\text { established checkpoints and quarantine facilities at border } \\
\text { crossings and in major cities (Ministry of Health 1985) } \\
\text { 1986: Notifiable Disease Designation-This policy designated } \\
\text { HIV/AIDS a Class B notifiable disease, requiring newly } \\
\text { identified cases be reported within } 24 \text { h (Ministry of Health } \\
\text { 1986) } \\
\text { 1986: Travel Ban Invoked-This policy instituted a ban on } \\
\text { entry into China by PLWH (Ministry of Public Security and } \\
\text { Ministry of Foreign Affairs 1986) } \\
\text { 1986, 1987, 1988: Foreigner Health Certificates - This series } \\
\text { of policies required that all foreigners seeking entry or } \\
\text { remaining in China for } 12 \text { months provide a certification of } \\
\text { health that included HIV status (State Education Commission } \\
\text { and Ministry of Health 1986; Ministry of Health and Ministry } \\
\text { of Public Security 1987; Ministry of Health et al. 1988). }\end{array}$ \\
\hline $\begin{array}{l}\text { 1989-1994: An outbreak of } \\
\text { HIV was discovered among } \\
\text { people who inject drugs } \\
\text { (PWID) in remote, rural } \\
\text { Yunnan province (Ma et al. } \\
\text { 1990; Shao et al. 1991; Zhang } \\
\text { et al. 1994). HIV began to } \\
\text { spread rapidly. By 1994, } \\
\text { roughly } 2000 \text { cases had been } \\
\text { reported in } 22 \text { of } 31 \\
\text { provincial-level administrative } \\
\text { areas }\end{array}$ & $\begin{array}{l}\text { The response of the Chinese Government during this period } \\
\text { was primarily punitive, attempting to combat HIV via } \\
\text { increased policing and organized "crackdowns" on drug use } \\
\text { and prostitution (Ministry of Health and Ministry of Public } \\
\text { Security of China 1991). Officials within China's Ministry of } \\
\text { Health (MOH) also began to discuss implementing behavioral } \\
\text { interventions among high-risk populations, including } \\
\text { providing STI testing and treatment for FSW (see Chaps. } 3 \\
\text { and } 7 \text { for more information) }\end{array}$ \\
\hline
\end{tabular}


Table 18.1 (continued)

\begin{tabular}{|c|c|}
\hline HIV epidemic status & Policy and response \\
\hline $\begin{array}{l}\text { 1995-2002: A much larger } \\
\text { outbreak of HIV was } \\
\text { discovered among FPD in } \\
\text { rural central China-HIV had } \\
\text { spread to tens of thousands of } \\
\text { poor farmers through unsafe } \\
\text { plasma collection practices } \\
\text { (Wu et al. 1995, 2001, 2008). } \\
\text { Meanwhile, HIV continued to } \\
\text { spread among PWID, FSW, } \\
\text { and other high-risk groups. } \\
\text { By } 1998 \text { all } 31 \text { provincial- } \\
\text { level administrative areas had } \\
\text { reported HIV cases. By 2002, } \\
\text { approximately 10,000 PLWH } \\
\text { had been diagnosed }\end{array}$ & $\begin{array}{l}\text { Senior-level officials within the Chinese Central Government } \\
\text { became aware of the seriousness of the HIV epidemic and the } \\
\text { critical and urgent need for a response, resulting in another } \\
\text { series of policies and actions: } \\
\text { 1995: Sentinel Surveillance-China CDC was directed to lead } \\
\text { the development and launch of a national sentinel surveillance } \\
\text { system to monitor the HIV/AIDS epidemic } \\
\text { 1996: Multi-Sector Coordination-The State Council STD/ } \\
\text { AIDS Prevention and Control Coordinating Meeting } \\
\text { Mechanism was established to strengthen cooperation } \\
\text { between government agencies } \\
\text { 1998: NCAIDS Established-The MOH created the National } \\
\text { Center for STD/AIDS Control and Prevention (NCAIDS) } \\
\text { within the China CDC, tasking it to provide technical } \\
\text { guidance for HIV/AIDS prevention and control nationwide } \\
\text { 1998: Blood Donation Law-This law ensured the safety of } \\
\text { blood for clinical use and safeguarded the health of blood } \\
\text { donors and recipients. It stressed that blood donation be } \\
\text { voluntary and devoid of compensation (Standing Committee } \\
\text { of the National People's Congress 1998) } \\
\text { 1998: Medium- and Long-Term Plan-The China Medium- } \\
\text { and Long-Term Plan for HIV/AIDS Prevention and Control } \\
\text { (1998-2010) encouraged condom use promotion as a means } \\
\text { of preventing sexual transmission of HIV (Ministry of Health } \\
\text { et al. 1998) } \\
\text { 2000: Delineation of Responsibilities-A policy entitled } \\
\text { Working Duty in HIV/AIDS Prevention and Control for } \\
\text { Related Ministries, Committees, Administrations and Social } \\
\text { Groups was issued to ensure responsibility and accountability } \\
\text { for different components of the HIV/AIDS response was clear } \\
\text { (Ministry of Health 2000) } \\
\text { 2001: First Five-Year Plan-The first Five-Year Action Plan } \\
\text { for the Containment and Control of HIV/AIDS (2001-2005) } \\
\text { was issued, setting up a regular planning cycle for the HIV } \\
\text { response and allowing the exploration of harm reduction } \\
\text { strategies such as MMT (State Council 2001) }\end{array}$ \\
\hline
\end{tabular}


Table 18.1 (continued)

\begin{tabular}{|c|c|}
\hline HIV epidemic status & Policy and response \\
\hline $\begin{array}{l}\text { 2003-2013: Improved } \\
\text { methods for estimating the } \\
\text { total number of PLWH were } \\
\text { implemented beginning in } \\
\text { 2005, yielding reliable } \\
\text { biennial estimates (Wang } \\
\text { et al. 2010). In 2005, an } \\
\text { estimated 650,000 were } \\
\text { infected. Just } 8 \text { years later in } \\
\text { 2013, the estimate was } \\
\text { 810,000 (Ma et al. 2018). } \\
\text { Nevertheless, the epidemic } \\
\text { remained concentrated both } \\
\text { geographically and within } \\
\text { high-risk groups, although } \\
\text { expansion to new high-risk } \\
\text { groups occurred (e.g., MSM; } \\
\text { Wu et al. 2013). Availability } \\
\text { and uptake of prevention, } \\
\text { harm reduction, testing, and } \\
\text { treatment services improved } \\
\text { during this time, and as a } \\
\text { result, more cases were } \\
\text { identified, and individual and } \\
\text { community outcomes } \\
\text { improved (He et al. 2013; } \\
\text { Zhang et al. 2009, 2011; Zhao } \\
\text { et al. 2013a, b), but extremely } \\
\text { poor retention in care was a } \\
\text { major problem (Gu et al. } \\
\text { 2016; Ma et al. 2018) }\end{array}$ & 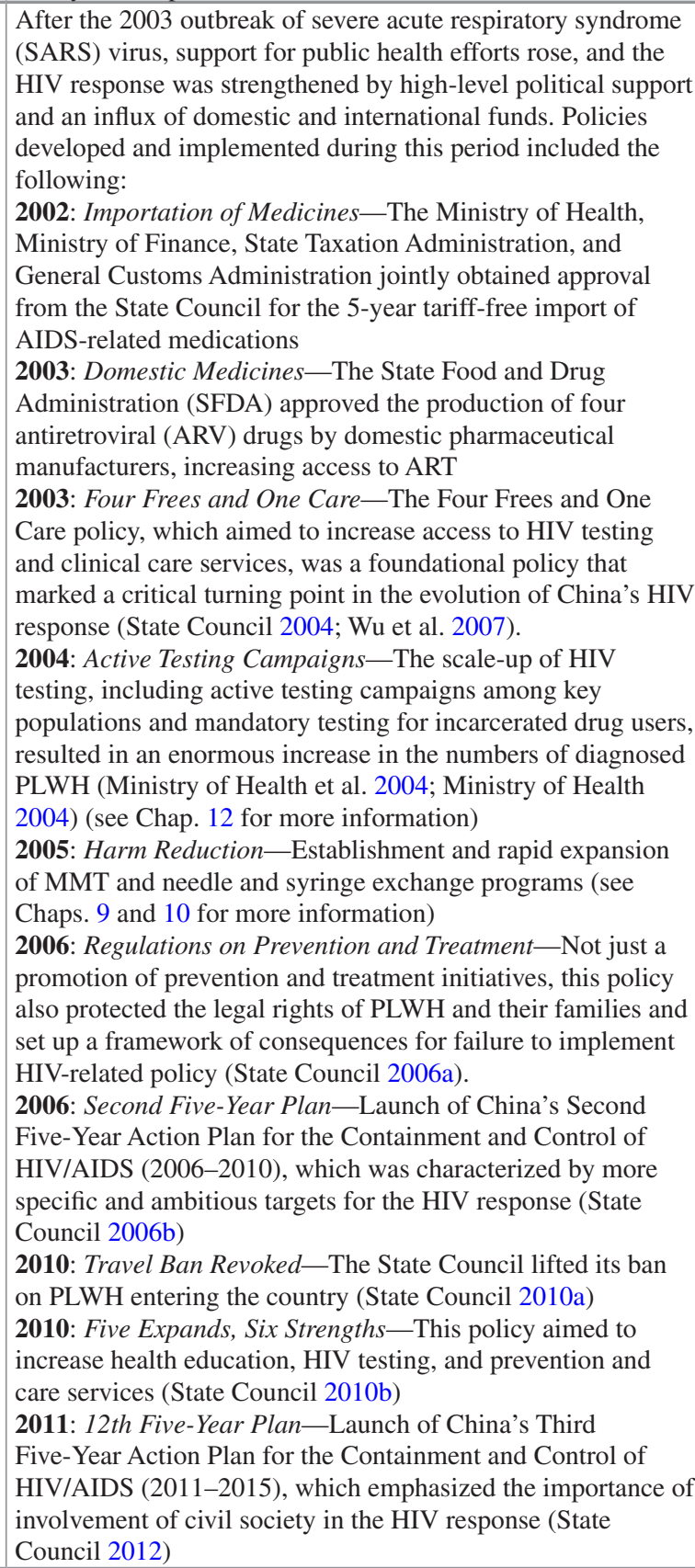 \\
\hline
\end{tabular}


Table 18.1 (continued)

\begin{tabular}{|c|c|}
\hline HIV epidemic status & Policy and response \\
\hline $\begin{array}{l}\text { 2014-Present: In 2014, } \\
\text { sexual transmission became } \\
\text { the primary driver of the } \\
\text { epidemic and MSM became } \\
\text { the high-risk group with the } \\
\text { fastest rise in prevalence } \\
\text { (National Health and Family } \\
\text { Planning Commission 2015) }\end{array}$ & $\begin{array}{l}\text { Two important changes in the global strategy to combat HIV/ } \\
\text { AIDS were influential during this period. First, the Joint } \\
\text { United Nations Programme on HIV/AIDS (UNAIDS) } \\
\text { 90-90-90 Targets refocused international efforts on improving } \\
\text { testing and treatment services and addressing poor retention in } \\
\text { care (Joint United Nations Programme on HIV/AIDS 2014, } \\
\text { b). Secondly, substantial evidence of individual and } \\
\text { community benefit of early ART led WHO to eliminate the } \\
\text { ART eligibility criterion and recommend ART for all PLWH } \\
\text { (World Health Organization 2016) } \\
\text { 2016: 13th Five-Year Plan-China's 13th Five-Year Action } \\
\text { Plan for the Containment and Control of HIV/AIDS (2016- } \\
\text { 2020) contained three very important changes in national } \\
\text { HIV-response strategy: (1) the 90-90-90 Targets were adopted } \\
\text { as a national strategy, (2) the CD4 count-based ART eligibility } \\
\text { criterion was eliminated, and (3) a new, streamlined and } \\
\text { accelerated protocol for PLWH to obtain a confirmed } \\
\text { diagnosis, complete clinical staging, and initiation of } \\
\text { treatment, the so-called "One4All" strategy, was adopted } \\
\text { (State Council 2017) }\end{array}$ \\
\hline
\end{tabular}

within China's Central Government came to realize that foreigners were not driving the HIV epidemic in China. In fact, between 2007 and 2009, foreigners accounted for only $0.3 \%$ of all newly identified HIV infections within China. Therefore, in 2010, the more than two-decades-old travel ban was finally revoked (State Council 2010a; Sun et al. 2010).

\subsubsection{Blood Donation Law}

In the mid-1990s, a massive outbreak of HIV infection was discovered among FPD in rural central and eastern China (Wu et al. 1995, 2001, 2008). Those affected were largely poor farmers who sold their blood to support their families. Domestic blood collectors and blood product manufacturers, finding themselves in a market suddenly shielded from international competition because of the ban on importation of foreign blood products, took advantage in the lag in government regulation and oversight of this new and highly lucrative market. Interest in growing profits eclipsed concerns for quality and safety, and the health of donors and recipients was compromised when equipment became contaminated and tens of thousands became infected with HIV. The outbreak became one of the worst tragedies of the global HIV pandemic (Sun et al. 2010; Wu et al. 2007).

In response to the crisis, blood collection stations were shut down within several weeks nationwide, and in 1996, China's Blood Donation Law was drafted. Enacted in 1998, the most important component of the law was the prohibition of blood 
donation outside nationally regulated blood collection facilities. However, the law also emphasized that blood donation must be voluntary, and donors may not be compensated (Standing Committee of the National People's Congress 1998). Since the enactment of the Blood Donation Law, only a handful cases of HIV infection via blood transfusion have been reported (Sun et al. 2010; Wu et al. 2007). Substantial effort has been made to develop standards and quality assurance programs to ensure the safety of the nation's blood supply. This has included improved testing methods to ensure that even a "window-period" donation (i.e. donation from an individual who is in the window period of infection when it is still undetectable by traditional antibody-based serological tests) is caught and removed before it enters the blood supply (see Chap. 6 for more information).

\subsubsection{China's First Five-Year Action Plan (2001-2005)}

To improve the coordination of the response to China's growing HIV epidemic, high-level representatives from the Ministries of Health, Finance, Public Security, and Justice, as well as the Development Commission met to discuss the introduction of harm reduction measures including MMT, needle and syringe exchange, and condom use promotion. The decision was made to move forward with formulation of policies supporting these measures and endorsing small pilot studies of harm reduction interventions. The result was that harm reduction strategies were included in China's First Five-Year Action Plan for the Containment and Control of HIV/ AIDS (2001-2005; State Council 2001; Sun et al. 2010).

Unfortunately, the plan was not sufficiently funded, which weakened its impact, particularly in its early years from 2001 to 2003. However, the SARS outbreak in 2003 caused public health to rise to the top of China's policy agenda, and funding was dramatically improved (Sun et al. 2010; Wu et al. 2007). Funding issues aside, the mere inclusion of harm reduction in the plan was a major step forward and a victory for public health specialists who had been advocating for harm reduction already for many years. Long-standing sociocultural barriers to harm reduction were beginning to fall away (see Chap. 19 for more information).

\subsubsection{The "Four Frees and One Care" Policy}

The massive HIV outbreak in central China among FPD led to a huge demand for treatment and care, as a growing proportion of this population progressed to advanced HIV disease and AIDS, and experienced high and increasing morbidity and mortality (see Chap. 1 for more information).

In response, the Chinese Government announced a major, new commitment to engage in a more comprehensive HIV response at the UN High-Level Special Meeting in late 2003. This commitment, which later became known as the "Four Frees and One Care" policy, included the following five promises: 
1. Free ART for AIDS patients in rural areas and those without medical insurance living in urban areas,

2. Free HIV voluntary counseling and testing (VCT) services,

3. Free ART for pregnant women living with HIV for the prevention of mother-tochild transmission (PMTCT) and free HIV testing for their HIV-exposed infants,

4. Free schooling for children orphaned by AIDS, and

5. Care and economic assistance to households of PLWH.

Implemented beginning in early 2004, the "Four Frees and One Care" policy has had an enormous impact on the HIV/AIDS epidemic in China (State Council 2004; Sun et al. 2010; Wu et al. 2007). Most importantly, it caused a dramatic increase in ART coverage for PLWH. Led by the National Free ART Program (NFATP) and facilitated by a massive support program called China CARES, the number of PLWH on ART in 2003 was only roughly about 100, but by 2005, this number had increased to 20,000 and by 2007, to 34,000 (Ma et al. 2018). ART scale-up had a major impact on HIV/AIDS-related mortality (Zhang et al. 2009), and as evidence of the benefits of ART accumulated, requirements restricting ART eligibility were relaxed and greater and greater proportions of PLWH who were diagnosed were receiving treatment (Ma et al. 2018). Additionally, HIV testing overall increased, and the number of pregnant women screened for HIV and provided PMTCT services increased dramatically. All children orphaned by AIDS were taken in by relatives, neighbors, or local government-run social welfare programs. Moreover, although not a primary objective of the policy, stigma and discrimination appeared to be positively impacted in the wake of the "Four Frees and One Care" policy, particularly in areas where the epidemic was driven by contaminated plasma collection (Cao et al. 2006) (see Chaps. 13, 25, and 28 for more information).

\subsubsection{Regulations on AIDS Prevention and Treatment}

In 2006, the Chinese Government issued the Regulations on AIDS Prevention and Treatment, which helped define the roles and responsibilities of the different relevant agencies within the government, civil society, and PLWH (State Council 2006a). However, it importantly was the first piece of legislation in China that dealt with the protections of the rights of PLWH. Stigma associated with HIV/AIDS has been very severe in China since the beginning of the epidemic. PLWH and their family members, neighbors, or friends have been discriminated against due to their medical diagnosis or their association with someone with an HIV diagnosis. Discrimination resulting from stigmatizing attitudes has been particularly severe in the workplace and in healthcare settings. This policy clearly set out, specifically, the right to marry, the right to access healthcare services, the right to equal employment opportunities, and the right to receive an education for all PLWH. The primary aim of the regulations was to address stigma and discrimination against PLWH and to create legal protection for politically sensitive prevention measures, particularly harm reduction interventions including MMT, needle and syringe exchange, and condom use 
promotion. It furthermore described consequences for failure to implement HIV/ AIDS-related policy. However, implementation and enforcement of this regulation has been inconsistent across geographies, levels of government, and sectors within the government (Sun et al. 2010). Nevertheless, this was a very important piece of legislation that again marked a turning point in China's HIV response (see Chap. 28 for more information).

\subsubsection{The Second Five-Year Action Plan (2006-2010)}

The new administration led by President Hu Jintao, Premier Wen Jiabao, and Vice Premier and then Minister of Health Wu Yi placed HIV policy high on the national agenda (Sun et al. 2010; Wu et al. 2007), and this more supportive political environment greatly facilitated the development of China's Second Five-Year Action Plan for the Containment and Control of HIV/AIDS (2006-2010; State Council 2006b). The plan set more specific and ambitious targets, particularly for prevention programs for marginalized, high-risk groups, such as PWID, FSW, MSM, and migrant workers. It also contained targets for harm reduction programs. For example, one target was to establish MMT clinics in all counties and cities with more than 500 registered drug users, and for MMT coverage to reach at least $70 \%$ of registered opioid users. This explicit target, and the funding associated with it, was instrumental in the successful scale-up the MMT program. Finally, the plan also contained targets related to treatment including ART coverage of at least $80 \%$ for AIDS patients by 2010 and PMTCT coverage of more than $90 \%$ for pregnant women living with HIV by 2010 (Sun et al. 2010).

\subsubsection{The "Five Expands, Six Strengths" Strategy}

The "Five Expands, Six Strengths" strategy was introduced in 2010, when the HIV epidemic was continuing to grow at an ever-faster rate despite the government's prior efforts-a large population of PLWH remained undiagnosed, and transmission dynamics were shifting more toward sexual contact, and new high-risk groups were becoming affected. This strategy was meant to combat the HIV epidemic with renewed focus and greater commitment. The five "expands" were expand coverage of (1) information, education, and communication (IEC) interventions; (2) HIV testing; (3) PMTCT services; (4) integrated interventions; and (5) ART services. The six "strengths" were strengthen (1) blood safety management, (2) health insurance, (3) care and support, (4) rights protections, (5) organizational leadership, and (6) response teams.

\subsubsection{The 12th Five-Year Action Plan (2011-2015)}

The estimated number of PLWH in China had climbed from 650,000 in 2005 to 700,000 in 2007, and then to 740,000 in 2009. Although the proportion of all PLWH 
who were diagnosed was improving, there was still a huge number of PLWH who did not know they were infected-74\% of all PLWH in 2007 were unaware of their status (Ma et al. 2018). Additionally, while the epidemic remained concentrated geographically and among key populations, new high-risk groups were being affected (e.g., MSM, migrants, serodiscordant couples) and more people were progressing to AIDS. China's HIV epidemic was becoming more dynamic and more complex. Thus, when it came time to draft the third plan for 2011-2015, policymakers had realized that the HIV response required renewed vigor and new measures that would increase the efficiency and effectiveness. Therefore, in the 12th Five-Year Action Plan for the Containment and Control of HIV/AIDS (2011-2015; called the 12th instead of the third to align with the national planning cycle), policymakers took a new direction, and for the first time, civil society was included as an important partner in the HIV response. The new plan heavily emphasized the need to support the involvement of organizations outside the government, such as nongovernmental organizations (NGOs) and community-based organizations (CBOs), in HIV prevention and care. This was groundbreaking and added much needed additional capacity for implementation of interventions. Additional key components of the plan included strengthening the prevention and control capacity of local administrative levels and further expanding coverage of prevention and care services (State Council 2012).

\subsubsection{The 13th Five-Year Action Plan (2016-2020)}

Already in 2014, sexual transmission had become the primary driver of China's HIV epidemic, and high-risk groups had changed-HIV among MSM was escalating at an alarming rate. In 2007, just $3.4 \%$ of all newly diagnosed cases were among MSM, but by 2014, 26\% were among MSM (National Health and Family Planning Commission 2015). At the same time, the epidemic overall was continuing to grow and the expansion of testing and treatment services were still lagging. The estimated total number of PLWH in China was 850,000 at the end of 2015, one-third of whom did not know their status (Ma et al. 2018).

Internationally, the global effort to combat the HIV pandemic was becoming increasingly coordinated by UNAIDS, among others. In 2014, UNAIDS, seeking to galvanize support and create momentum for further expansion of treatment, launched a new, ambitious goal for the global HIV response. It took the form of what has been named the 90-90-90 Targets. These targets are 90\% of all PLWH know their status, $90 \%$ of all diagnosed PLWH are on treatment, and $90 \%$ of all PLWH on treatment achieve viral suppression by 2020 (Joint United Nations Programme on HIV/AIDS 2014). The targets placed emphasis not just on scale-up of ART but on finding the many people who still do not know they have HIV infection, getting them onto life-saving and community-protecting treatment, and helping them to achieve the goal of that treatment, viral suppression (Joint United Nations Programme on HIV/AIDS 2017). It has stimulated countries, like China, to take a closer look at the failings of their HIV care continua from HIV screening to treatment to clinical outcomes. 
Additionally, by 2015, considerable, high-quality evidence from both observational studies and clinical trials had accumulated, demonstrating the significant individual clinical benefits and community preventive benefits of early ART (i.e. treating HIV infection with antiretroviral drugs before $\mathrm{CD}^{+} \mathrm{T}$-lymphocyte populations declined below 500 cells $/ \mathrm{mm}^{3}$ ). Therefore, in 2016, WHO announced revised treatment recommendations. Historically, it had recommended that only PLWH with low CD4 counts receive ART, and although this criterion had been expanded over time, from $<200$ cells $/ \mathrm{mm}^{3}$ to $<350$ cells $/ \mathrm{mm}^{3}$ and then to $<500$ cells $/ \mathrm{mm}^{3}$, it was now eliminating the requirement altogether recommending that all PLWH, regardless of CD4 count receive ART (World Health Organization 2016).

In the meantime, China had been examining its HIV care continuum and had already been studying the effects of early ART for expanded populations of PLWH in the Chinese setting. As of 2015, it had not yet met the 90-90-90 targets, but it had measured performance against them and found that $68 \%$ of its PLWH were diagnosed, $67 \%$ of its diagnosed PLWH were on ART, and $65 \%$ of its PLWH on ART had achieved viral suppression (Ma et al. 2018). It had also examined loss to followup along the continuum ( $\mathrm{Gu}$ et al. 2016) and found that creating a simplified and streamlined patient pathway, known as the "One4All" strategy, from screening HIVreactive to receiving a confirmed diagnosis to being initiated on ART, regardless of CD4 count, had important clinical benefits including a dramatic reduction in allcause mortality (Wu et al. 2015, 2017).

Thus, when it came time for the State Council to draft its next five-year plan, some very important strategic changes were included. The 13th Five-Year Action Plan for the Containment and Control of HIV/AIDS (2016-2020) adopted the 90-90-90 Targets as a national strategy, eliminated the CD4 count-based ART eligibility criterion, and incorporated the "One4All" strategy (State Council 2017).

\subsection{Challenges and Future Directions}

China has made enormous progress over the past 30 years, and in particular in the most recent 15 . However, China faces a myriad of challenges in responding to its HIV epidemic and the needs of its affected citizens. By the end of 2015, an estimated 850,000 people in China were living with HIV, but only 574,000 (68\%) had been diagnosed. Among those diagnosed, only 383,000 (67\%) were receiving treatment. Clearly, there is still a long way to go toward the ultimate goal of elimination of HIV infection (Ma et al. 2018).

Stigma and discrimination are still unacceptably prevalent and cause the vulnerable and the marginalized to choose not to access prevention, testing, treatment, and care services for fear of being exposed. Consistent condom use, one of the most effective and affordable prevention measures available, is still low both among heterosexual couples and homosexual couples as well as in the context of extramarital noncommercial and commercial sexual contact. Harm reduction measures still do not cover all those in need of services, and retention is 
persistently poor. Testing uptake even among those who are aware and knowledgeable, educated, and financially stable is suboptimal-many do not access testing frequently enough, and many more have never tested. HIV VCT services are slow, PITC services are poorly targeted and routinely identify infection too late, and self-testing, which could be very promising for reaching those who choose not to access facility-based or government-run testing services, suffers from a lack of regulation, quality assurance, and linkage to care mechanisms. Enormous numbers of PLWH who screen HIV-reactive or are diagnosed with HIV infection are lost to follow-up before they start treatment due to fragmented services, long wait times, complicated procedures, and difficulty in navigating a complex health system. Those who do successfully start treatment struggle with follow-up and adherence to medications and often do not achieve the all-important treatment goal of viral suppression. Furthermore, treatment for coinfections such as hepatitis B virus, hepatitis $\mathrm{C}$ virus, and tuberculosis is not integrated into HIV services. Together, these factors contribute to high mortality and morbidity even among China's treated PLWH.

Since the beginning of China's HIV/AIDS epidemic, leaders and policymakers have sought to find pragmatic solutions, tailored to the Chinese context, aligned with international best practices, and grounded in the best available information at the time. However, implementation of existing policy has been uneven and inconsistent and more importantly, China's epidemic has changed, and China itself has changed. New, innovative approaches must be developed, and bold steps must be taken, if China's current HIV epidemic is to be confronted and controlled.

Acknowledgments The author would like to thank Jonas Tillman for editorial assistance.

\section{References}

Cao X, Sullivan SG, Xu J, Wu Z, China CIPRA Project 2 Team. Understanding HIV-related stigma and discrimination in a "blameless" population. AIDS Educ Prev. 2006;18(6):518-28. https:// doi.org/10.1521/aeap.2006.18.6.518.

Gu D, Mao Y, Tang Z, Montaner J, Shen Z, Zhu Q, et al. Loss to follow-up from HIV screening to ART initiation in rural China. PLoS One. 2016;11(10):e0164346. https://doi.org/10.1371/ journal.pone.0164346.

He N, Duan S, Ding Y, Rou K, McGoogan JM, Jia M, et al. Antiretroviral therapy reduces HIV transmission in discordant couples in rural Yunnan, China. PLoS One. 2013;8(11):e77981. https://doi.org/10.1371/journal.pone.0077981.

Joint United Nations Programme on HIV/AIDS. "Three Ones" key principles. Geneva: Joint United Nations Programme on HIV/AIDS; 2004. http://data.unaids.org/una-docs/three-ones_ keyprinciples_en.pdf. Accessed 25 Sep 2018.

Joint United Nations Programme on HIV/AIDS. 90-90-90 - an ambitious treatment target to help end the AIDS epidemic. Geneva: Joint United Nations Programme on HIV/AIDS; 2014. http:// www.unaids.org/sites/default/files/media_asset/90-90-90_en.pdf. Accessed 27 Sep 2018.

Joint United Nations Programme on HIV/AIDS. Ending AIDS— progress towards the 90-90-90 targets. Geneva: Joint United Nations Programme on HIV/AIDS; 2017. http://www.unaids.org/ sites/default/files/media_asset/Global_AIDS_update_2017_en.pdf. Accessed 27 Sep 2018. 
Lin W, Chen S, Seguy N, Chen Z, Sabin K, Calleja JG, et al. Is the HIV sentinel surveillance system adequate in China? Findings from an evaluation of the national HIV sentinel surveillance system. Western Pac Surveill Response J. 2012;3(4):76-85. https://doi.org/10.5365/ WPSAR.2012.3.3.004.

Ma Y, Li Z, Zhang K. Identification of HIV infection among drug users in China. Chinese J Epidemiol. 1990;11:184-5.

Ma Y, Dou Z, Guo W, Mao Y, Zhang F, McGoogan JM, et al. The human immunodeficiency virus care continuum in China: 1985-2015. Clin Infect Dis. 2018;66(6):833-9. https://doi. org/10.1093/cid/cix911.

Mao Y, Wu Z, Poundstone K, Wang C, Qin Q, Ma Y, et al. Development of a unified web-based national HIV/AIDS information system in China. Int J Epidemiol. 2010;39(Suppl 2):ii79-89. https://doi.org/10.1093/ije/dyq213.

Ministry of Health. Notice on banning import of blood products such as factor VIII. Beijing: Ministry of Health, People's Republic of China; 1984.

Ministry of Health. Report on strengthening surveillance to prevent imported cases of HIV/ AIDS. Beijing: Ministry of Health, People's Republic of China; 1985.

Ministry of Health. Notice on strengthening HIV/AIDS management. Beijing: Ministry of Health, People's Republic of China; 1986.

Ministry of Health. Working duty in HIV/AIDS prevention and control for related ministries, committees, administrations and social groups. Beijing: Ministry of Health, People's Republic of China; 2000.

Ministry of Health. Notice on HIV screening of former plasma donors. Beijing: Ministry of Health, People's Republic of China; 2004.

Ministry of Health, Ministry of Foreign Affairs, Ministry of Public Security. Several provisions concerning HIV surveillance and management. Beijing: Ministry of Health and Ministry of Public Security, People's Republic of China; 1988.

Ministry of Health, Ministry of Public Security. Provisions concerning the provision of health certificate by foreigners seeking entry. Beijing: Ministry of Health and Ministry of Public Security, People's Republic of China; 1987.

Ministry of Health, Ministry of Public Security. Notice on providing compulsory testing and treatment of sexual transmitted diseases for sex workers and their clients. Beijing: Ministry of Health and Ministry of Public Security, People's Republic of China; 1991.

Ministry of Health, Ministry of Public Security, Ministry of Justice. Notice on HIV screening of inmates of prisons and detoxification centers. Beijing: Ministry of Health, Ministry of Public Security, and Ministry of Justice, People's Republic of China; 2004.

Ministry of Health, State Development Planning Commission, Ministry of Science and Technology, Ministry of Finance. China's medium and long-term plan on prevention and control of HIV/ AIDS. Beijing: Ministry of Health, State Development Planning Commission, Ministry of Science and Technology, and Ministry of Finance, People's Republic of China; 1998.

Ministry of Public Security, Ministry of Foreign Affairs. Rules for implementation of the law of the People's Republic of China on control of the entry and exit of aliens. Beijing: Ministry of Public Security and the Ministry of Foreign Affairs, People's Republic of China; 1986.

National Health and Family Planning Commission. 2015 China AIDS response progress report. Beijing: National Health and Family Planning Commission, People's Republic of China; 2015. http://www.commuhealtibet.org/wp-content/uploads/2016/11/CHN_narrative_report_2015. pdf. Accessed 27 Sep 2018.

Shao Y, Chen Z, Wang B, Zeng Y, Zhao SD, Zhang ZR. Isolation of viruses from HIV infected individuals in Yunnan. Chinese J Epidemiol. 1991;12:129.

Standing Committee of the National People's Congress. Blood donation law of the People's Republic of China. Beijing: Standing Committee of the National People's Congress, People's Republic of China; 1998.

State Council. China's action plan for reducing and preventing the spread of HIV/AIDS (20012005). Beijing: State Council, People's Republic China; 2001. 
State Council. Notice on strengthening AIDS prevention, treatment and care programs. Beijing: State Council, People's Republic China; 2004.

State Council. Regulations on AIDS prevention and treatment. Beijing: State Council, People's Republic of China; 2006a.

State Council. Action plan on HIV/AIDS prevention and containment (2006-2010). Beijing: State Council, People's Republic of China; 2006b.

State Council. Rules for implementation of the law of the People's Republic of China on control of the entry and exit of aliens. Beijing: State Council, People's Republic of China; 2010a.

State Council. Notice on strengthening AIDS prevention, treatment and care programs. Beijing: State Council, People's Republic China; 2010b.

State Council. China's action plan for reducing and preventing the spread of HIV/AIDS (20112015). Beijing: State Council, People's Republic China; 2012.

State Council. Thirteenth five-year action plan for controlling HIV/AIDS in China (2016-2020). Beijing: State Council, People's Republic of China; 2017.

State Education Commission, Ministry of Health. Notice on performing HIV test for foreign students. Beijing: State Education Commission and Ministry of Health, People's Republic of China; 1986.

Sun X, Lu F, Wu Z, Poundstone K, Zeng G, Xu P, et al. Evolution of information-driven HIV/ AIDS policies in China. Int J Epidemiol. 2010;39(Suppl 2):ii4-13. https://doi.org/10.1093/ije/ dyq217.

Wang N, Wang L, Wu Z, Guo W, Sun X, Poundstone K, et al. Estimating the number of people living with HIV/AIDS in China: 2003-09. Int J Epidemiol. 2010;39(Suppl 2):ii21-8. https:// doi.org/10.1093/ije/dyq209.

World Health Organization. Consolidated guidelines on the use of antiretroviral drugs for treating and preventing HIV infection - recommendations for a public health approach. Geneva: World Health Organization; 2016. http://apps.who.int/iris/bitstream/handle/10665/208825/9789241549684_eng. pdf;jsessionid=6EB9CCB5EDBD29972688DFFF0481ACF7?sequence=1. Accessed 27 Sep 2018.

Wu Z, Liu Z, Detels R. HIV-1 infection in commercial plasma donors in China. Lancet. 1995;346(8966):61-2.

Wu Z, Rou K, Detels R. Prevalence of HIV infection among former commercial plasma donors in rural eastern China. Health Policy Plan. 2001;16:41-6.

Wu Z, Sullivan SG, Wang Y, Rotherum-Borus MJ, Detels R. The evolution of China's response to HIV/AIDS. Lancet. 2007;369(9562):679-90. https://doi.org/10.1016/S0140-6736(07)60315-8.

Wu Z, Dong N, Guo W. Discovery and control of the HIV/AIDS epidemic among plasma donors in China. In: Li LM, Zhan SY, editors. Epidemiological research cases in China. Beijing: People's Medical Publishing House; 2008. p. 153-64.

Wu Z, Xu J, Liu E, Mao Y, Xiao Y, Sun X, et al. HIV and syphilis prevalence among men who have sex with men: a cross-sectional survey of 61 cities in China. Clin Infect Dis. 2013;57(2):298309. https://doi.org/10.1093/cid/cit210.

Wu Z, Zhao Y, Ge X, Mao Y, Tang Z, Shi CX, et al. Simplified HIV testing and treatment in china: analysis of mortality rates before and after a structural intervention. PLoS Med. 2015;12(9):e1001874. https://doi.org/10.1371/journal.pmed.1001874.

Wu Z, Tang Z, Mao Y, VanVeldhuisen P, Ling W, Liu D, et al. Testing and linkage to HIV care in China: a cluster-randomised trial. Lancet HIV. 2017;4(12):e555-65. https://doi.org/10.1016/ S2352-3018(17)30131-5.

Zhang J, Chen H, Duan S, Duan Y, Zhao S, Wang S, et al. The epidemic of HIV infection in Yunnan (1989-1992). Chinese J Epidemiol. 1994;15:259-62.

Zhang F, Dou Z, Ma Y, Zhao Y, Liu Z, Bulterys M, et al. Five-year outcomes of the China National Free Antiretroviral Treatment Program. Ann Intern Med. 2009;151(4):241-51. https://doi. org/10.7326/0003-4819-151-4-200908180-00006.

Zhang F, Dou Z, Ma Y, Zhang Y, Zhao Y, Zhao D, et al. Effect of earlier initiation of antiretroviral treatment and increased treatment coverage on HIV-related mortality in China: a national observational cohort study. Lancet Infect Dis. 2011;11(7):516-24. https://doi.org/10.1016/ S1473-3099(11)70097-4. 
Zhao Y, Shi CX, McGoogan JM, Rou K, Zhang F, Wu Z. Methadone maintenance treatment and mortality among HIV-positive people who inject opioids in China. Bull World Health Organ. 2013a;91(2):93-101. https://doi.org/10.2471/BLT.12.108944.

Zhao Y, Li C, Sun X, Mu W, McGoogan JM, He Y, et al. Mortality and treatment outcomes of China's National Pediatric Antiretroviral Therapy Program. Clin Infect Dis. 2013b;56(5):73544. https://doi.org/10.1093/cid/cis941. 